of the "water-doctor having done him more good than any one." From that time, nearly twelve months ago, I refused to have anything to do with him; he had returned to his old drinking propensities, of the certain results of which he was warned by myself and by others, among them by Mr. Trent, a gentleman of the highest respectability residing near this place; to whose warning Probart replied, " that if it killed him he could not leave off the drink." During these months I frequently spoke to him in the street. On one occasion he said he was taking acid and laudanum in large quantities, by the advice of a kind lady." Later still I saw him with a swelled and ghastly face, and all the appearance of a dying man. Inquiring the cause, he replied, "They gave me a deal of mercury, and did not tell me; I went out, and got wet and cold, and my gums and throat were so sore and swelled that I could not swallow for upwards of a week. I fecl all rotting inside." He was soon laid up again, and Dr. Hastings and Mr. Addison went on with their treatment. Here, then, is a poor man who had been destroying his constitution for years by every kind of intemperance, subjected in a careless manner to the destructive effects of mercury, which ended, as every scientific medical practitioner might have anticipated in such a case, in dropsy, utter destruction of the constitution, and death. And yet Dr. Hastings, because it serves a certain purpose, has the effrontery to assert that a short treatment by myself, nearly twelve months previous, followed by comparative health for three months, was the cause of his death, and not, as is evidently the case, the result of the poor man's own imprudence, assisted by the most unjustifiable and injudicious treatment on the part of Dr. Hastings. God forbid that I should for a moment harbour the thought, or suppose this to be more than error on the part of his medical attendants. However, Sir Astley Cooper says (in the " Lancet," A pril, 1824), "Mercury is by no means an unfrequent cause of dropsy," and a host of medical writers enumerated by Dr.Copland in his " Dictionary of Practical Medicine," art. Disease of the Heart, say that "long-continued intemperance causes disease of the heart."

I have the honor to be, Gentlemen,

Yours obediently,

James Wilson.

Great Malvern, Aug. 14, 1843.

[The passages which we have omitted are so utterly irrelevant to the case of Probart, are so personal and libellous in their character, and partake so much of the nature of an empirical advertisement, that we cannot think of occupying our pages with them. In the individual instance of Probart the question is purely one of credibility between Dr. Hastings and Mr. Addison, two gentlemen of unblemished reputation and the highest professional character, on the one hand, and Dr. Wilson on the other. In a postscript to his letter, which we subjoin, Dr. Wilson requests the insertion of a favorable case as a set-off to the case of Probart. We would, however, observe that Dr. Kinglake could have produced many such, but the question is not whether gout may be occasionally cured under the cold-water treatment, but whether this treatment can be safely had recourse to. To this subject, however, we purpose to return on another occasion.]
P.S.-I may also in fairness request the insertion of the following authenticated case as a set-off to the one you have published, which was intended, and most likely will injure my professional reputation and interests :-

\section{CASE OF GOUT.}

Malvern, Sept. 16, 1842.

My Dear Sir,-I cannot take leave of Malvern without again expressing to you my thanks for the encouragement you gave me to try the effect of the water-cure as you practise it, and for your kind attention to me during the time I have undergone the treatment. I have now gone through the perspiring process, followed by the bath, fifty times, with the other parts of the treatment; I found them anything but disagreeable, indeed I may say quite the reverse, and they have been most beneficial to me. During nine months before I came here I was never able to move without my crutches, and a great part of that nine months I passed in my bed or on the sofa. My nights were restless, my pulse high, and my tongue charged. I am now turned sixty-three years of age, and have been subject to the gout more than forty years; I paid little attention to it for the first twenty years, and as soon as the fit was over I never missed taking my wine daily. My knees, hands, and other parts were so crippled that I had made up my mind to pass the rest of my days in my arm-chair or bed, or to hobble about with my crutches. The effect of the treatment has so ameliorated my situation, that I can now go up and down stairs with ease and comfort without a stick, and the other day walked half a mile on the high road. I frequently ride on horseback four hours a-day, and my general health, I thank God, is as well as ever it was in my life; I sleep well, my appetite is good, I can use my arms freely, and tie my neckcloth-a thing I had not been able to do for years; in fact, I feel myself comfortable and independent. Had I come here a year ago, and undergone the same process, I have no doubt but I should have saved my left knee from being contracted; as it is, I am contented to walk a little lame, and shall be too happy to remain in the same state $I$ am in at present for the rest of my days. Pray excuse this long scrawl, as I know you have not a minute to spare, and believe me,

\section{My dear Sir,} Yours most truly,

\section{Park-hall, Epping, Essex.}

$$
\text { T. C. Marsh. }
$$

\section{6, Rue Matignon, Paris.}

P.S.-It is now nearly twelve months since this letter was written; and a few weeks ago Admiral Beauman received a letter from Mr. Marsh, in which he stated that " he is still in perfect health, with every prospect of continuing so."-J. W.

\section{PROPOSED TEST OF THE COLD-WATER CURE.}

TO THE BDITORS OF THE PROVINCLAL MEDICAX JOURNAL.

Gentlemen,-It is, I believe, alleged that the cold-water treatment, so called, is sufficient to cure all curable diseases, and that medicines are, therefore, useless, if not injurious. It occurs to me that it 
might be ascertained by a very easy and simple experiment, not whether the above allegation be true, for that could not be ascertained in the positive, except by an inquiry almost as boundless as animated nature itself, and occupying not the life of one man, but many successive ages; but it might be easily ascertained by a very simple experiment, whether the cold-water treatment is sufficient to cure one single disease.

Let a given number of patients-say six or twelve -laboring under the same disease, be placed in any public hospital-let the cold-water treatment be applied to one-half the number, and the ordinary medical treatment to the other half, and let the result be examined, and reported on at the end of a given time.

It will not be right to select for the experiment patients in fever, or small-pox, or measles, or scarlatina; because recovery takes place in all these diseases, more or less frequently, under every method of treatment, and the cases of recovery under medical treatment are not regarded, except by the quack or i gnorant patient, as cases of cure, but only as cases of recovery, more or less aided by the medical treatment. Besides, there would be a moral impropriety in making these severe and dangerous diseases the first subjects of an experiment that might, possibly, compromise life.

It will not be right to select rheumatic, or gouty, or dyspeptic, or hypochondriac patients, both because they also recover under a great variety of methods of treatment, and because gouty and rheumatic pains, and hypochondriac and dyspeptic sensations may be simulated, or recovery may be alleged to have taken place where it has not, or not to have taken place where it has.

A disease should, therefore, be selected which is,

First, Of such a nature that an experiment may be made on it with safety to the patient.

Secondly, Which is visible and tangible, and what cannot be simulated or misrepresented, or misunderstood.

Thirdly, From which there is no spontaneous or natural recovery, and in which, therefore, if recovery takes place, it is fairly attributable to the remedies used; and,

Lastly, A disease for which medical art at present possesses a certain remedy.

The disease commonly called psora, or the itch, possesses all these requisites, and is, therefore, suited for the experiment. Let six itch patients, therefore, be subjected to the cold-water treatment, and six more to the common medical treatment by sulphur, and let the results be compared at the end of a fortnight. It will be then ascertained whether the cold water treatment can cure one single diseare, and if it does, whether it does so as speedily, as certainly, and with as little trouble and expense to the patient as the present medical method.

If the result of the trial in this disease is favorable to the cold water system, further trials upon a similar plan may then be made on other diseases, and the real merits of the system satisfactorily ascertained. If the result of this first experiment be unfavorable to the system, the statement of its propounders and partisans must be modified, so that instead of saying it cures all curable diseases, they must limit themselves to the statement that it cures all curable diseases except the simplest and most easily curable of all, the itch.

I am, Gentlemen,

Your obedient humble servant, JAMEs HeNRY, M.D.

Fitzwilliam-square, Dublin, Sept. 13, 1843.

\section{PRIVILEGES OF THE ROYAL COLLEGE OF PHYSICIANS.}

TO THE EDITORS OP THE PROVINCLAL MBDICAL JOURNAL.

Gentremkn,-Your remarks in reply to my former letter are so far satisfactory, as they admit that the College of Physicians has the right to give a license to practise as a physician, independently of the possession of a diploma from any university. Such a license, indeed. is all that the laws of the kingdom require, in order for any one to act as a physician; and any degrees or diplomas that the physician may be additionally possessed of, excepting only a degree from Oxford or Cambridge, can merely be regarded in the light of honorary distinctions, and as conferring no right or privilege whatever.

It is well known that the great majority of provin. cial physicians possess only these honorary degrees; and that they consequently are altogether illegal practitioners; but although this is the case, I am far from wishing, in the present confused state of medical polity, that such practitioners should in any way be interfered with, possessing, as I believe them generally to do, the moral qualifications for practising as physicians; yet, as a medical reformer, though with a conservative bias, I do not therefore think it unimportant for us to recollect the true state of the case. So much for the legal right of extra and intra licentiates of the college, who are not graduates of an university, to practise as physicians.

With regard to their intrinsic qualifications and moral right, these I cannot but regard as perfectly satisfactory, when we recollect the extended character of the curriculum of the college, particularly that part of it which requires at least three years' attendance on the medical practice of a British hospital; to which may be added the practical character of the examination by the president of the college and three of the elects.

There can, indeed, be no doubt in the mind of any one who is acquainted with the acts of Parliament relative to the subject, that when the College of Physicians, five or six years since, " vindicated its claims to be the source of professional honox, by regarding in the same light, and addressing by the same appellation, all who have obtained its diploma, whether they had graduated elsewhere or not," it overstepped neither the opirit nor lettex of the laws, which have invested it with the power of governing and legislating for the whole faculty of medicine within its jurisdiction.

\section{I am, Gentlemen,}

Your obedient servant,

Medicus. 